\title{
Elbistan Havzası Yazılı Kültür Ortamında Gazetelerde Yer Alan Karşılaşma-Atışma-Deyişme Örnekleri*
}

\author{
Bedri ÖZÇELİ** \\ Fatma Ahsen TURAN***
}

Öz

Edebi metinlerin oluşumunda coğrafya her zaman etkili bir unsur olmuştur. Elbistan Havzası'nın kültürel değerleri, bu yörede önemli bir yere sahip olan halk şiiri geleneğinin oluşum, gelişim ve devamına katkı sağlamıştır. Halk şiiri geleneği içinde yer alan karşılaşma, atışma ve deyişme tarzı şiirler bu şiirin diğer örnekleri gibi sözlü kültür ortamında meydana gelmiştir. Ancak toplum hayatının şekillenmesine etki eden gelişmeler yeni kültür ortamlarının doğmasını sebep olmuştur. Bunlar; yazılı ortam, elektronik ortam ve sanal ortamdır. Sözlü kültür ortamında oluşan söz konusu şiir türleri zamanla yazılı ve elektronik ve sanal kültür ortamlarında da görülmeye başlanmıştır. Elbistan Havzası'nda etkili olan yerel gazetecilik yörede yazılı kültür ortamının gelişmesine katkı sağlamıştır. Bu coğrafyanın halk şiiri tarzında şiir yazan kalem şairleri eserlerini özellikle de karşılaşma, atışma ve deyişme türündeki şiirlerini yerel gazeteler aracılığıyla halka duyurmuş̧tur. Halk, gazetede yayımlanan bu tarz eserlere ilgi duyduğundan bu kültür coğrafyasında bu tür yazılı söyleşmeler gelişerek devam etmiştir. Yerel gazetelerde yayımlanan şiirler, 2006'dan itibaren bir araya getirilerek kitap halinde basılmıştır. Bu şekilde oluşmuş dört eser tespit edilmiştir. Söz konusu eserler, sözlü kültür ortamında doğan ve yazılı kültür ortamında devam eden karşılaşma, atışma ve deyişme geleneğini devam ettirmeleri bakımından önemli bulunmuş ve değerlendirilmiş̧ir.

Anahtar Kelimeler: Elbistan Havzası, Halk Şiiri, Yazılı Kültür Ortamı, Gazete, Karşılaşma, Atışma, Deyişme

\footnotetext{
*Bu makale, hazırlanmakta olan "Elbistan Havzası Halk Şiiri Geleneği ve Abdurrahim Karakoç’un Şiir Dünyası" adlı doktora tezinden üretilmiștir.

** Öğr. Gör., Kırıkkale Üniversitesi, Kırıkkale, Türkiye.

Ankara Hacı Bayramı Veli Üniversitesi, Lisansüstü Eğitim Enstitüsü, Türk Dili ve Edebiyatı Ana Bilim, Türk Halk Edebiyatı Bilim Dalı, Doktora Programı, Doktora Öğrencisi, Ankara, Türkiye.

Elmek: bedri.ozcelik@hbv.edu.tr

https://orcid.org/ 0000-0002-7589-2731

*** Prof. Dr., Ankara Hacı Bayramı Veli Üniversitesi, Edebiyat Fakültesi, Türk Dili ve Edebiyatı Bölümü Öğretim Üyesi, Ankara, Türkiye.

Elmek: fatma.turan@hbv.edu.tr

https://orcid.org/ 0000-0002-0645-6012
} 


\title{
Examples of Encountering-Quarrel- Dialogue in the Newspapers in the Elbistan Basin Written Culture Environment
}

\begin{abstract}
Geography in the formation of literary texts has always been an influential factor. The cultural values of the Elbistan Basin contributed to the formation, development and continuation of the folk poetry tradition, which has an important place in this region. Encountering, quarrel and dialogue types poems, which are included in the folk poetry tradition, occurred in the oral culture environment like other examples of this poem. However, developments affecting the shaping of social life led to the emergence of new cultural environments. These environments are written environment, electronic environment and virtual environment. These poetry types formed in the oral culture environment have start to be seen in written and electronic and virtual culture environments over time. Local journalism which is effective in the Elbistan Basin, was contributed to the development of the written cultural environment in this region. The pen poets of this geography, who wrote poetry in the style of folk poetry, were announced their works, especially poems of types encountering, quarrel and dialogue to the public through local newspapers. Since the public is interested in these kinds of works published in the newspaper, in this cultural geography, such written dialogues have continued to develop. The poems published in local newspapers have been put together as a book since 2006. Four works that were formed in this way were identified. The works in question were found important and evaluated because they continued the encountering, quarrel and dialogue tradition that were born in the oral culture environment and develop in the written culture environment.
\end{abstract}

Keywords: Elbistan Basin, Folk Poetry, Written Culture Environment, Newspaper, Encountering, Quarrel, Dialogue 


\section{Extended Summary}

The first literary qualified works of the Turkish nation are poetry. The first examples of poetry occurred in the oral tradition. These formed the basis of Turkish folk poetry. However, it has been determined by scientific studies that folk poetry has also existed in different cultural environments over time. This study has been prepared in order to show both how the examples of encountering, quarrel and dialogue that were shaped and developed in an oral cultural environment emerged in the written culture environment that emerged with social change and development, and the reflections of these examples emerging in the written culture environment on the Elbistan Basin.

Is geography an effective factor in the formation of culture and literature?

Is it possible to see folk poetry genres such as encountering, quarrel and dialogue that occurred and developed in the oral culture environment in time in the written culture environment?

Which way does poems such as encountering, quarrel and dialogue differ?

Why were these types of poetry published mostly in newspapers, which are written cultural media instrument?

Why is it important to book these poems published in newspapers?

Newspapers published in Kahramanmaraş and its surroundings, encyclopedias and books providing information about the region were accessed and scanned. At the same time, the statements of the source people, whose opinions were consulted during the fieldwork, also contributed.

It has been determined that there is a healthy harmony between the aim of the study and the opportunities offered by the resources. Although there are encountering, quarrel and dialogue samples published in newspaper media belonging to some regions, these examples were not found in a collected into a book.

Literature study on the subject has been done. During the fieldwork, the information obtained from the source people was noted, and studies were carried out in the archives of local newspapers. 
The information obtained from basic sources, source people and local press archives was scanned and notes were made card index. The necessary planning has been made and then the work has begun.

In the introduction, it has been determined why Elbistan Basin is a center of culture and civilization. Then, information was given about the encountering, quarrel and dialogue examples seen in the written culture medium. In the next part, the importance of the newspaper in the world of culture and literature is emphasized. In the following paragraphes of the same part, examples of folk poetry published in newspaper environment and followed with interest by readers are emphasized. In the next part, information was given about the process of converting the encountering, quarrel and dialogue published in newspapers into a book and a brief introduction of these books was made. While creating these parts, methods of comparison, interpretation, sampling and proving the opinions put forward with documents were used. In particular, the contents of the examples published as a book were handled with the book method.

It has been observed that the encountering, quarrel and dialogue, which occured in the oral cultural environment and which are the basic elements in the chapters of minstrels, continue effectively in the written culture environment. It has been determined that this situation still preserves its vitality in the Elbistan Culture Basin, which also includes the northern districts of Kahramanmaraş.

The fact that the geographical element is important in the formation and development of culture and literature has manifested itself in the cultural and literary activities in the Elbistan Basin.

Folk poetry will survive as long as the nation exists. For this reason, it is natural that there are changes in the culture environment in which it occurs. Folk poetry continues to exist in written and electronic culture media.

Encountering, quarrel and dialogue differs in that encountering is aimed at checkmate, quarrel is oriented towards humor, and Dialogue is oriented towards conversation.

The main factor that causes encountering, quarrel and dialogue style poems to be published in local newspapers is that the poets who work in the style of folk poetry in the Elbistan Basin are pen poets and therefore they produce 
their poems by writing. The second factor is the desire to find collocutor for these kinds of poems.

The printing of encountering, quarrel and dialogue published in local newspapers in the form of a book will ensure that such works are presented systematically and the tradition reaches the future in a complete manner. For this reason, the mutual dialogues of pen poets in local newspapers have been published as a book. These book-capacity works are important in terms of being the first in the field of studies in the Elbistan Basin. 



\section{Giriş}

Coğrafi çevre, insan ve toplum; kültürün temel unsurları arasında yer almaktadır. Bu durum değişik coğrafi çevrelerde yaşayan ve farklı karakterlere sahip insan gruplarına özgü, birbirlerinden bağımsız hars değerlerinin doğmasına sebep olmuştur (Kafesoğlu, 1988: 202). Bir ülkenin farklı coğrafi bölgelerinde oluşan maddi ve manevi değerleri, içerisinde bulunduğu bazı kültürel normlarla uyum içindedir. Bununla birlikte her coğrafyanın kendine özgü davranış kalıpları o yörenin kendine has irfanını ortaya çıkarır. Bu farklılıklar o yörelere ait kültürün norm ve değerlerinden kaynaklanmaktadır. Yöreye ait maddi ve manevi unsurlar; kendine özgü hayat tarzı, değerleri, normları, tutum ve davranışlarıyla çevreye yansımıştır. Bu yansımalar insan ile mekân arasındaki ilişkiyi ortaya koymuş ve kültür coğrafyasının doğmasına zemin hazırlamıştır.

Mekânları değerli kılan o beldelerin ruhu ve irfanıdır. Bu ruh ve irfanı ise o yerin maddi ve manevi değerleri olarak kabul edilen; tarihi, coğrafyası, tabiatı ve iklimi kazandırır (Oguzbaşaran 2006: 37-39).

Gökalp (1981: 21)'in dile getirdiği gibi hars, "bir milletin dinî, ahlâkî, hukukî, bedii, lisani, iktisadi, fennî hayatlarının ahenkli mecmuasıdır.” Onun zikrettiği bütün bu unsurlar toplumun fertleri tarafindan paylaşılır ve yaşatılır. $\mathrm{Bu}$ bedii unsurlar arasında milletin edebiyatı ve sanatı da yer alır.

Hayat tarzı haline getirilmiş kültürün ögeleri arasında yer alan halk şiiri, içinde yaşadığı ve yaşatıldığı coğrafyayla yakından ilgilidir. Halk şiiri geleneğinin devam ettiği yörelerden biri de Kahramanmaraş ve çevresidir. Bu yöre, iki coğrafi bölümden oluşmaktadır. Kahramanmaraş'ın kuzey ilçelerini içine alan ve Elbistan Havzası ${ }^{1}$ olarak adlandırılan coğrafya ile Kahramanmaraş merkez, Andırın ve Türkoğlu ilçelerinin yer aldığı yöredir. Üzerinde çalışma yapılan mekân Kahramanmaraş'ın kuzey ilçelerinin büyük kısmını içine alan Elbistan Havzasıdır. Bu Havza’nın tercih edilme sebebi burada çok sayıda şairin yetişmesiyle, yörenin önemli sanat ve edebiyat merkezi olmasıyla yakından alakalıdır.

1 Elbistan Havzası, Dulkadiroğlu Beyliği’nin yaklaşık iki asır boyunca başkentliğini yapmış olan Elbistan ile Afşin, Ekinözü, Göksun ve Nurhak gibi yerleşim birimlerinden oluşmaktadır. Çalışmada söz konusu ilçelerin adlarının tek tek kullanımı yerine "Elbistan Havzası" ifadesi tercih edilmiștir. 
Milli varlıklarını koruyan ve yaşatan toplumlarda halk şiiri, hâlâ yerini korumakta ve bu irfan hazinesine bağlı olarak gelenek yeni ortamlarda yeni tarzlarla varlığını sürdürmektedir. Elbistan Havzası, değerlerini toplumsal hafızasında taşıyan ender yörelerden biridir. Bu yöredeki halk şiiri örneklerinin günümüze kadar gelmesinde kültür ortamlarının varlığı etkili olmuştur. Sözlü şiir geleneğinde, sözlü kültür ortamından yazılı kültür ortamına ve elektronik kültür ortamına geçişler art zamanlı ve eş zamanlı bir ilişki içinde gerçekleşmiştir. İster sözlü, ister yazıll, isterse de elektronik ortam etkili olsun milleti millet yapan kültür her daim varlı̆̆ını geliştirerek sürdürmüştür. Ong'un (1999:14) da ifade ettiği gibi "Art zamanl çerçeve içinde geçmiş ve gelecek, Homeros şiirleri ve televizyon birbirine tşılk tutabilir."

\section{Yazılı Kültür Ortamında Karşılaşma-Atışma-Deyişme}

Sözlü edebiyat geleneği, binlerce yıllık bir dil birikiminin sonucudur. Bu dil, aynı zamanda yazılı geleneğin de malzemesidir. Sözün yazıya geçirilmesi ile malzemesi dile dayanan edebi eserlerin sözlü gelenek dışında yazılı gelenekte de nesilden nesile aktarıldığı ve kültür tarihi içinde sözlü gelenekle ile yazılı gelenek arasında etkileşim olduğu görülmüştür (Elçin 1992: 5-6). Bu yüzden yazılı ortamda oluşan şiire, sözlü şiir birikiminin etkisi inkâr edilemez. Sözlü ortamda olgunlaşan halk şiiri, yazılı edebiyatın oluşumunun temel kaynaklarından biridir. Milletlerin milli ve manevi gelişimleri süreklilik arz eder. Kültürü oluşturan her ortam, kendinden önceki ortamdan etkilenmiş ve kendinden sonraki ortamın oluşmasına katkı sağlamıştır. Kültür ortamlarının tamamen sona ermesi söz konusu değildir.

Çobanoğlu, halk şiirinin yazılı ortamda yer alışını şu iki düşünceye dayandırmaktadır: Birincisi "âşsı ve halk şiirinin cönk ve mecmualarda toplanma geleneğinin kahvehanelerin teşekkülünden sonra ortaya çıkması yahut yaygınlaşması ve kahvehanelerle birlikte merakl grupların oluşmaya başlaması" düşüncesidir. İkincisi ise; "kahvehanelere devam eden divan ve tekke edebiyatı sanaţ̧larının şïrlerini yazarak muhafaza etmeleri" (2000: 139) görüşüdür. Bu düşüncelerden yola çıkarak yazılı kültür ortamının oluşmasında sözlü kültür ortamının önemli mekânı kahvehanelerin ve bu mekânlardaki kültürel etkileşimin etkili olduğunu söylemek mümkündür.

Ali Duymaz ise sözlü gelenekten yazılı geleneğe geçişte cönklerin fonksiyonu üzerinde durmuş ve bunu şekilde dile getirmiştir: "Cönkler, sözlü 
geleneği yazıll ürünler haline getirerek "tarihsel süreklilik" sağlamaya çalışmanın ilk ürünlerini içeren defterler olarak karşımıza çıkarlar. (...) O halde cönkleri bir medenî değişim sürecinin eşiğinde "sözlü geleneği” farkl ortamlara aktararak yaşatma çabası olarak görmeliyiz." (2016: 26).

Âşık tarzı halk şiirinin de cönklerde ve mecmualarda yer alması; sözlü geleneğin farklı icra ortamlarında varlığını sürdürmesine, bu tür eserlere ilgi duyanların nitelik ve niceliğinin artmasına, yerellik algısının değişmesine katkıda bulunmuş; yazılı olmakla kalıcı hale gelmesinin önü açılmıştır. Sözlü icra ortamından yazılı kültür ortamına geçiş süreci cönklerle ve mecmualarla sınırlı kalmamış, matbaanın ve taşbaskı tekniğinin kullanımıyla âşık tarzı halk şiiri ürünleri yazılı ortamda geniş kitlelere ulaşma imkânı bulmuştur

Ong’a göre; matbaanın kullanılmaya başlanmasından sonra "ikincil sözlü kültür" dönemine geçilmiş, bu dönemin "birincil sözlü kültür" dönemiyle bir takım otak özellikler taşımasına rağmen söz konusu dönemde halk şairlerinin "söz söyleme ortamları" çeşitlenmiş ve ikincil sözlü kültür ortamında "söz”, yazılı ve elektronik ortamlarda da kuşatıcı bir kimliğe bürünmüştür (Ong 1999). "Sözün sürekli etkileşimde bulunduğu bu üç kültür ortamı da "kendilerine has kurallara bağlı geleneklerin oluşmasında uygun birer zemin” (Özarslan 2001: 207) oluşturmuştur.

XX. yüzyılda siyasi dönüşümlerin oluşturduğu ekonomik, teknolojik, bilimsel ve sosyal farklılıklar, âşık tarzı halk şiirinin geleneksel icra ortamlarını büyük oranda değiştirmiştir. Bu değişime neden olan hususlar, yazılı ortamdaki yöntemleri öncelikli hale getirmiştir. XX. yüzyılın ikinci yarısı ve XXI. yüzyılın ilk çeyreğinde geleneğin boyut değiştirerek devam etmesine sebep teşkil eden gelişmeler olmuştur. Yerel gazete ve dergilerin çıkması ve teknolojik ilerlemeler söz konusu gelişmelerdendir. Bu gelişmeler halk şiiri geleneğini etkilemiş ve halk şiirinin icra ortamları olarak kabul edilen kültür ortamları değişmiştir. İcra ortamlarındaki bu değişim sebebiyle geçmişi asırlar öncesine dayanan ${ }^{2}$ ve sözlü gelenekle tarih sahnesine çıkan halk şiiri, mevcut icra ortamlarının yanı sıra yeni mekân ve ortamlarda vücut bulmuştur. Sözlü şiirimizin sanatçıları olan âşıllar, halk şairleri

2 Konuyla ilgili geniş bilgi için bakınız: (Köprülü 1915; Gökalp 1922; Boratav 1937; Özerdim 1943; Arat 1965; Günay 1992; Ata Y1ldiz ve Turan 2016) 
sanatlarını farklı meclis ve ortamlarda sunmuşlardır. Bu değişim sözlü ortamlardan yazılı olana doğru seyir takip etmektedir. Halk şiiri, yeni icra ortamlarında yeni formatlarla varlığını sürdürmeye devam etmiş̧ir.

Matbaanın gelişiyle yazılı metinler yaygınlık kazanmış, ulaşılması ve tanınması kolaylaşmıştır. Matbaanın XX. yüzyılda etkili şekilde kullanılması "Anadolu Basını" kavramını ortaya çıkarmış, yerel gazeteler ve dergiler âşıkların şiirlerini kitlelerle buluştururken, âşıklar da kitlelerle bu tarz iletişimin gereklerine uyan bir şiir üslubu geliştirmişlerdir (Oğuz 2006: 138-179). Âşık tarzı halk şiiri söyleyen şairler, gazetelerde yayımlama yoluyla şiirlerini paylaşma ve yayma imkânına kavuşmuşlar ve böylece "yeni bir icra ortamını" da kullanmaya başlamışlardır. Bu yeni icra ortamında gazeteler vasıta olarak kullanılmıştır (Şapolyo 1971: 266). Yazılı ortam, âşıkların yetişmesi, ürünlerin geniş kitlelere tanıtılması açısından alana önemli katkılar sağlamıştır (Artun,2011: 81). Elbistan Havzası'nda da halk şiiri geleneğinde önemli yere sahip olan karşılaşma-atışma ve deyişmeler gazete ile kalııı hâle getirilmiştir.

"Sözlü iletişim insanları birleştirir: Yazı ve okuma ise kişinin tek başına yaptığı ve kendi iç dünyasına döndüğ̈̈ eylemlerdir" (Ong 1999: 87). Ong'un da vurguladığ1 gibi sözlü iletişim insanları birleştirdiğinden sözlü icra ortamında birden fazla sanatçı ortak mekânda, benzer sosyal statüdeki dinleyici kitlesi önünde ortak ayakla karşılaşma, atışma ve deyişme tarzında metinler icra etmişlerdir. Yazma ve okuma bireysel bir eylem olduğu için ne mekânda, ne de ulaşılan okuyucu kitlesinde ortaklık aranmaz. Bu sebeple verilmiş olan örnek metinlerin genelinde ortak ayak bulunmamaktadır.

Halk şiiri geleneği içerisinde "karşılaşma, atışma ve deyiş̧me” önemli bir yere sahiptir. Umay Günay (1999:47) karşılaşmanın en az iki âşı̆̆ın dinleyici huzurunda veya herhangi bir yerde karşı karşıya gelerek, birbirlerini sazda ve

\footnotetext{
3 Türk Halk Edebiyatında terminoloji problemlerinin çoğu henüz tam olarak çözülememiştir. Karşılaşma, atışma ve deyişme hususunda da bu problem mevcuttur. Terimlerin anlamlarıyla ve kullanımlarıyla ilgili farklılıklar bu yüzdendir. Daha geniş bilgi için bknz: Günay, U. (1993). Türkiye'de Âşık Tarzı Şiir Geleneği ve Rüya Motifi. Ankara: Akçağ Yayınları, Artun, E. (2011). Âşıklık Geleneği ve Âşık Edebiyatı Edebiyat Tarihi/Metinler. 4. Baskı Adana: Karahan Kitabevi, Kaya, D. (1999). Karşılaşma, Atışma ve Deyiş̧me Kavramları Üzerine Düşünceler ve Feymani'den Örnekler. Folklor/Edebiyat Dergisi(20), 131-140, Özder, M. A. (1965). Doğu İllerimizde Âşık Karşılaşmaları. Bursa, Taşlıova, M. M. (2017). Âşıklık Geleneğinde Grup İcrası Group Performance in the Tradition of Minstrelsy. Milli Folklor, (113), 5-16. Atmaca Seher (2018). Kahramanmaraşlı Kalem Şairlerin Atışma Örnekleri, Sosyal Bilimler Dergisi / The Journal Of Social Science Yı1: 5, Sayı: 19, Ocak 2018, S. 178-203, Eke, M. (2000). "Saz Âşıklarında Atışma (Karşılaşma, Deyişme)", , C. 6,. Folklor Edebiyat Dergisi, 6(3), 193.
} 
sözde belli prensipler içinde denemeleri esasına dayandığını söylemektedir. Başgöz (1986:254) karşılaşma başlamadan önce âşıkların endişelerini yenmek için "Medet senden sarı telli kepçe" dediklerini söyler. Bu ifade âşı̆̆ın karşılaşmadaki yarışma, çekişme ve kendini gösterme zaruretinin ve kaybetme endişesinin bir tezahürüdür.

Karşılaşmaların sistematiği ise şöyle tasnif edilmiştir: 1. Hoşlama-merhabalaşma 2. Hatırlatma- canlandırma 3. Tekellüm a Serbest konulu tekellüm b. Öğütleme c. Bağlama-muamma d. Sicilleme e. Yalanlama f. Taşlama-takılma g. Tüketmece-daraltma h. Uğurlama-medhiye. Geleneğe göre karşılaşmadaki bu bölümleri ya ev sahibi konumundaki âşı ya da en yaşlı veya üstat kabul edilen âşık açar (Günay 1999: 47-60). Hatırlatma bölümündeki ayağı veren ilk aşığın söylediği 15 hecelik divanîye, muhatabı olan âşığın yine 15 hecelik divanî ile cevap vermesi örneğinde olduğu gibi, bu kişiler tarafindan verilen ayak, konu, ölçü ve şekil kuralına diğer âşıklar da riayet eder. Umay Günay (1999:49) da fası1 sistematiğini anlatırken özellikle bu hususu vurgular.

Karşılaşma, Kaya'nın da ifade ettiği gibi en az iki âşı̆̆ı̆ irticali olarak durumlarını, düşüncelerini, bilgi ve tecrübelerini sergilemek, dinleyenleri eğlendirmek veya birbirlerine üstünlük sağlamak için belirli kurallar çerçevesinde manzum olarak söyleşmeleridir (Kaya 1999: 133). Âşıklar birbirlerine karşı üstünlüklerini sergileme, rakiplerini sınama, yenme çabalarında ise soru-cevap usulü, dar ayak veya çift kafiyeli ayak kullanmaktadırlar. Bu yönüyle "karşılaşma" daha özel bir durum arz eder ve "atışma" ile "deyişme" den ayrılır (Kaya, 1999:133).

Atışmalar ise rakibi hedef alan, onun âşıklık konusunda yeterli olmadığını iddia eden, zaman zaman onu aşağılayan şiirlerden oluşur. Saldırı ve savunma anlayışının hâkim olduğu bu şiirlerde rakibi beğenmeme, kendini daha yetenekli görme gibi tavırlar takınılır (Artun, 2011: 92).

Deyişmelerde ise -hoşça vakit geçirme amacı taşıdığından- muhabbet esastır (Kaya 1999: 131-140). Deyişmelerin konusu âşıkların ilgi alanındaki her şey olabilir.

Teknolojik gelişmeler ve sosyo-kültürel hayatta meydana gelen değişimler sebebiyle "karşılaşma, atışma ve deyişme" lerin sözlü ortamda icra edilmesinde eskiye oranla bir azalma olmuş, bu tarz söyleyişler yazılı icra ortamında varlığını 
sürdürmüştür. Bu geleneğin yeni şartlar içinde yaşaması ve gelecek kuşaklara aktarılması günümüzde devam etmektedir. Halk şiiri geleneğinin yaşatıldığ1 önemli merkezlerinden biri olan Elbistan Havzası'nın halk şairleri; karşılaşma, atışma ve deyişme türlerine sahip çıkarak bu geleneğin yeni şartlarda nasıl sürdürülebileceğini edebiyat dünyasına göstermişlerdir (Avc1 2017: 10).

Halk şairleri her dönemde ve her ortamda kendilerini ifade edebilmişler ve kendilerinin rakiplerinden daha üstün niteliklere sahip olduklarını hissettirmeyi önemsemişlerdir. Bunu her ortamda da göstermişlerdir. Buna yazılı ortamda icra edilmiş karşılaşmalarda, atışmalarda ve deyişmelerde de rastlanmaktadır. Yazılı ortamda oluşan halk şiiri tür ve şekilleri serbest deyişlerdir (Günay 1993: 25). Çünkü yazılı kültür ortamında halk şairleri şiirlerini doğaçlama olarak değil tasarlayarak, yazarak ve üzerinde değişiklikler yaparak dinleyiciye ve okuyucuya sunmaktadır. Halk şairlerinin serbest deyişlerle meydana getirdikleri şiirleri daha çok yazılı kültür ortamının vasıtaları olan mektup ve gazete aracıllğıyla okuyucuyla buluşmuştur. Çalışmada yazılı kültür ortamının önemli vasıtası olan gazetede yayımlanan metin örnekleri üzerinde durulmuştur.

\section{Elbistan Havzası'ndaki Gazetelerde Yayımlanan Karşılaşma- Atışma-Deyişme Örnekleri}

Ahmet Hamdi Tanpınar, gazete hususunda "Hiçbir yerde gazete bizdeki role benzer bir rol oynamamıştır. Başka yerlerde o, düşüncenin daha geniş surette topluma yayılması için seçtiği hareket sahalarından biridir. Arkasında bütün cemiyet müesseseleri ve devam hâlinde olan, hayatla daima münasebet kuran bir düşünce dünyası vardır. Bizde ise bütün işaretler oradan gelir. Kalabalı onun etrafinda kurulur. Okumayı o yayar. Mekteplerin uzak bir gelecek için hazırladı̆̆ ocağı o tutuşturur." demektedir (Tanpınar 2009: 231). Tanpınar'ın bu tespitleri Türk toplumunun gazeteye yüklediği misyonu göstermesi bakımından önemlidir. Ulusal gazetelerin yanı sıra Anadolu'daki "yerel gazeteler" de bir mektep vazifesi ifa etmişlerdir. Gazete, Türkiye'nin eğitimli ve entelektüel gençlerle ileri gidebileceğini göstermiştir. Bu nedenle kültürün en önemli kolunun da edebiyat ve şiir olduğu vurgusu bu alanda eserler neşredilerek ortaya konulmuştur. Gazetenin amac1 toplumun kültür birikimini geliştirmek, edebiyat ve şiirle yoğrulmuş insanların sayısını arttırmak olmuştur (Özgen 2018: 462). 
XIX. yüzyılda çıkan gazetelerin ${ }^{4}$ sahiplerinin ve yazarlarının çoğunlukla edebiyatçı olması edebiyatın gazetede önemli bir mevki edinmesinde rol oynamıştır (Çıkla 2009: 39). İstanbul'da 1860'll yıllarda yayımlanan gazetelerden sonra XX. yüzyılın başlarından itibaren Anadolu'da da gazeteler çıkarılmaya başlanmıştır. Maraş'ta çıarılan ilk yerel gazete 1920'de yayın hayatına başlayan "Amâl-i Milli$y e$ " kabul edilmiştir. Cumhuriyet döneminde yayımlanan ilk yerel örnek ise " $M a$ raş" gazetesi olarak tespit edilmiştir. Maraş Valiliği kontrolünde faaliyet gösteren bu gazete, 1934-1948 y1lları arasında yayımlanmıştır (Özgen 2018: 462-463).

Elbistan Havzası yazılı kültür ortamında karşılaşma-atışma-deyişmelerin icrası için hem Maraş'ın merkezinde hem de taşra ilçelerinde çıkarılan yerel gazetelerin önemi büyüktür. Bu yerel gazeteleri ve onların faaliyetlerini kısaca şu şekilde ifade etmek mümkündür:

1 Nisan 1947 tarihinde Kahramanmaraş'ta yayın hayatına başlayan Engizek gazetesi, Dr. Kemal Tolun tarafından çıkarılmıştır (Özgen 2018: 463). Engizek gazetesi, yayın hayatını 1963 yılına kadar aralıksız sürdürmüştür (Polat 2009:190192). Söz konusu gazetede çeşitli edebi eserlere yer verilmiştir. Gazetenin birinci sayfanın sağ alt köşesi halk şiirlerinin yayımlandığı bölüm olarak hazırlanmıştır. Bu bölümde, koşma, ağıt, destan gibi halk şiiri örneklerinin yanı sıra tanınan veya yeni tanınmakta olan pek çok halk şairinin hayatına ve şiirlerine de yer verilmiştir. Maraş ve çevresinin dışında Erdemli, Tarsus gibi farklı yörelerden olan halk şairlerinin şiirleri de bu yerel gazetede yer almıştır. Okuyucu tarafından beğenilen şiirlerin şairlerine gazete sahiplerince posta yoluyla gazete gönderilmiştir.

Engizek gazetesinde yer alan şiirlerde Maraş'ın tarihi eserleri, tabiat varlıkları, kültürel değerleri ve kahramanlık gibi sosyal konular ele alınmıştır. Elbistan Havzası'nın yetiştirmiş olduğu XX. asrın önemli şairi olan Abdurrahim Karakoç'un her kesim tarafından zevkle okunan ve dinlenen "Mihriban" şiiri ilk olarak Engizek gazetesinde yayımlanmıştır. 1953 yılında Maraş’ı en güzel anlatan şiir yarışmasında, halk şairi Fikret Çeliksert'in şiiri birincilik ödülü almış, bu başarı gazetede haber yapılmış, söz konusu haber metni okuyucuların dikkatlerini edebî bölüme yoğunlaştırmıştır. Gazeteye olan ilginin artmasına rağmen gazetede

4 Osmanlı Devleti’nde ilk resmi gazete olan Takvim-i Vakayi 1831 yılında, Ceride-i Havadis Gazetesi de 1840 yılında yayın hayatına başlamıştır. 22 Ekim 1860 günü çıkmaya başlayan Tercüman-1 Ahval’in "bizde gündelik gazeteciliğin doğmasına sebep olması bakımından ehemmiyeti vardır." (Özön 1938: 1). 
yayımlanan bazı şiirlere de ağır eleştiriler yapılmıştır. Buna, örnek olarak halk şairi Talat Eren'in "Bahtsız Maraş" şiiri verilebilir. Maraş'ın diğer şehirler nazarında gelişmeden pay alamadığından yakınılmaktadır. Şairin bu konuyu gündeme getirmesi tenkit edilmiş ve bu tenkitler gazetede yer almıştır (Akyıldız 2018: 324-329). Gazeteler bu yönüyle bir mektep vazifesi görmüştür.

Özellikle halk şairlerinin karşılaşmaları, atışmaları ve deyişmeleri sözlü ortamda sivri ve keskin dille hicve varma noktasında devam ederken; gazetede, daha yumuşak bir dilin kullanılmasını tavsiye eden ikaz yazıları da yazılmıştır.

Bunun dişında edebî intihaller de gazetede konu edilmiş ve Maraş'ın başka bir gazetesi olan "Kahraman Yurt”"ta yayınlanan bir şiirde intihalin olduğu iddiası haber olarak sunulmuştur. Buradan hareketle Engizek'in edebî ürünlerin basımı ve yayımlanmasında özel bir hassasiyet taşıdığı söylenebilir (Yakar 2010).

Maraş fikir ve sanatına mührünü vuracak olan "Demokrasiye Hizmet" ise 19 Haziran 1950'de yayımlanmaya başlar (Özgen 2018: 463). Bu gazetede müstakil fikir yazılarının yanı sıra kültür-sanat yazılarına da yer verilmektedir. Gazetede Elbistan Havzası'nın yetiştirdiği halk şairlerinin şiirlerinin yanı sıra pek çok halk şairine ve şiirlerine de yer verilmiştir. Burada şiirlerine yer verilen halk şairleri şunlardır; Durdu Yoksul, Hayati Vasfi, Adil Soydan, Ahmet Bertizlioğlu, Ahmet Çıtak, Aş̧ı Mehmet, Hacı Ay, Hacı Zülkadir, Mehmet Göçer, Mevlüt Soydan, Arif Zülkadiroğlu, Asşık Hacı vs. 'dir (Yakar 2010).

Elbistan Havzası'nda geleneğe hizmet eden gazeteleri çıkış tarihine göre şu şekilde sıralamak mümkündür. Elbistan Postası (28 Ağustos 1957), Elbistan'ın Sesi (30 Temmuz 1960) (İlk adı "Elbistan Postasl" olan gazete, üç yıl sonra "Elbistan'ın Sesi" adı altında, günlük olarak yayın hayatına devam eder) Afşin'in Sesi (1972), Yeşil Afşin (1983), Haber Elbistan (Kasım 2002), Elbistan Kaynarca (1 Temmuz 2002), Vizyon (2002, Bizim Elbistan (29 Ekim 2003), Elbistan Gündem Haber (2010), Elbistan Manşet (9 Ağustos 2010), Elbistan Havadis (26 Kasım 2011), Havadis (2016) ve Göksun Kent (Polat 2009).

Kahramanmaraş merkezde çıkan gazetelerden sonra 1957 'den itibaren Elbistan Havzası'nda da halk şiiri örnekleri yazılı kültür ortamının önemli bir vasıtası olan yukarıda isimleri verilen gazeteler yayımlanmaya başlamıştır. Havza'da, 
“yerel basın” yazılı ortamının önemli icra aracı olmuştur. Elbistan Havzası halk şairlerinin meydana getirdiği yazılı karşılaşma, atışma ve deyişme örnekleri daha çok bu yöredeki ilçelerde yayımlanan yukarıda isimleri verilen gazetelerde yer almıştır

Yazılı ortamlarda icra edilen türlerle ilgili uygulamalar gelenekselleşerek günümüze kadar gelmiştir. Yazılı karşılaşma, atışma ve deyişme geleneğinin yaşayan önemli temsilcisi Mehmet Gözükara'nın konuyla ilgili düşüncesi şu şekildedir: "Afşin-Elbistan yöresinin âşıkları, şairleri, düşünce insanlarının da Kahramanmaraş coğrafyasında ayrı bir yeri vardır. Genelde halk âşıklarının bir geleneği olan atışmanın bizim gibi kalem şairlerinin de yapabileceğini gördük. Belki sazımız olsaydı böyle bir çalışma meydana gelmeyecek söylediklerimiz kulaklarda kalacak, uzaklara gitmeyecekti.” (Gözükara-Atmaca 2014: 22-23).

Günümüzde halk şiiri geleneğini yeni şartlar içinde yaşatmaya ve geliştirmeye çalışan halk şairleri mevcuttur. Bunlar; Türk milletinin geleneğini, göreneğini, örf ve adetlerini benimseyen, bu değerleri hayat prensibi haline getiren, halkın duygu ve düşüncelerine tercüman olan sanatçı şahsiyetlerdir. Bu sanatçıların çoğu kalem şairi olduğundan şiirlerini saz eşliğinde söyleyerek değil, yazarak ortaya koymuşlardır. Özellikle âşık tarzı halk şiiri geleneğinin yakın bir zamana kadar canlı bir şekilde sürdürüldüğü Elbistan Havzası'nda, halk şiiri bu halk şairleri tarafından sazsız bir miras olarak günümüzde yaşatılmaktadır (Avc1 2014: 13-18).

Gazetelerdeki yazılı karşılaşma, atışma ve deyişme örneklerine Anadolu'nun pek çok yerinde rastlamak mümkündür. Bu tür şiir örneklerine özellikle Kahramanmaraş'ın kuzey ilçelerinde de çok fazla ilgi duyulmuş olup günümüzde özellikle Elbistan Havzası'nda yayımlanan gazetelerde söz konusu şiir örnekleri hâlâ canlılı̆̆ını korumaktadır (Erşahin 2014: 10).

Havza'da yayımlanan yerel gazetedeki ilk örnek Ahmet Çıtak ile Hayati Vasfi Taşyürek'in birbirlerine yazmış oldukları 23 Eylül-09 Kasım 1957 tarihlerinde Elbistan Postası gazetesinde yayımlanan muhtelif türlerden oluşan metinler mevcuttur (Bilgin 2010: 250-264).5 Ahmet Çıtak, 1957 yılının zor şartlarında, Elbistan'dan Afşin'e üç günde ancak gidebilen Hayati Vasfi’ ye yönelik “küçüm-

5 Karşılaşma, atışma ve deyişme metinlerinin tamamı Arif Bilgin tarafından hazırlanarak 01.01.2012 tarihine Elbistan’’n Sesi gazetesinde "Çıttak Ahmet ile Hayati Vasfi Taşyürek’in 1957deki Atışmaları" adıyla yeniden yayımlanmıştır. 
seyici, hor görücü ve imtihan edici" bir tarzda şiir yazmış ve bunu dönemin etkili yerel gazetesi olan Elbistan Postası'nda yayımlamıştır. Şair, "Malamatlık derya olmuş boyuna /Gir içine yüz bakalım Hayati" dizelerinde hem rakibinin perişanlığını gündeme getirerek onu yermiş hem de ona bir muamma sormuştur. "Benim gibi bir belada kalmışı/Sen de bana yaz bakalım Hayati" dizelerinde de rakibin hedef alındığını, onun âşıklık konusunda yeterli olmadığının iddia edildiğini görmekteyiz. Söz konusu “atışma” dan alınan dörtlükler şöyledir:

\section{Hayatî ${ }^{6}$}

"Nüfus kâtibinden haberin aldım,

Şan misali gez bakalım Hayati

Şekeri okşayan hatıra saldım

Şerbetini ez bakalım Hayati

Üç günde Afşin"e ancak gelmişin

Aralıkta çok perişan olmuşun

Benim gibi bir belada kalmışın

Sen de bana yaz bakalım Hayati

Şairsin, dilinde hazır silahın

Yoksa gücendi mi sana ilahın

Var mı ola acep gizli günahın

Suçlarını süz bakalım Hayati

(...)

Ahmet Çıtak hayran güzel huyuna

Itiraz edilmez temiz huyuna

Malamatlk derya olmuş boyuna

Gir içine yüz bakalım Hayati” 
Hayati Vasfi, bir hafta sonra Ahmet Çıtak'a cevap vermiştir. Vasfi, bu cevapta Çıtak'ın sorduğu muammayı çözdüğü gibi aynı zamanda ona yönelik övgülerini ve yergilerini de dile getirmiştir. O, bu cevabıyla kendisinin de Çıtak'tan geri kalmayacak güçte bir şair olduğunu göstermiştir. Şiirini "Muhterem Ahmet Çıtak'a" ismiyle Elbistan Postası gazetesinde yayımlamıştır. Ahmet Çıtak'ın şiirinde kullanmış olduğu "malamatllk" kelimesinin ebced hesabında neye tekabül ettiği Vasfi'nin bu şiirinde açıklanmış, muhatabının sorduğu muamma Vasfi tarafından çözülmüştür. Hayati Vasfi, yazmış olduğu cevabında Çıtak'a yönelik dokundurmalar yapmış, onun üst perdeden şiir söyleyerek rakibini küçük görmesini eleştirmiştir. Hayati Vasfi, "Gördüğün aşığa dost taşı vurmak/Engin gidenlerin kalbini kırmak /Hal hatı zamanı muamma sormak / Sendeki değişmez huy Çıtak Ahmet" diyerek Ahmet Çıtak'1 eleştirmiştir. "Âşsklar verdiği eserle büyür /Ömrüyle beraber şanı da yürür /İlmin afakını duman mı bürür /Asıl aşk ebedi, hay Çıtak Ahmet”' diyerek de nasihat etmiştir. Hayati Vasfi'nin yazmış olduğu

“atışma” nın bir bölümü aşağıda verilmiştir:
Ahmet Çıtak ${ }^{7}$
"Aldım selamını okudum hazla
Bilirim coşkundur, bey Çıtak Ahmet
Şad olmadım gitti baharla, yazla
Kara baht elinden oy, Çıtak Ahmet
Gördüğün aşığa dost taşı vurmak
Engin gidenlerin kalbini kirmak
Hal hatır zamanı muamma sormak
Sendeki değişmez huy Çıtak Ahmet
Âşılklar verdiği eserle büyür
Ömrüyle beraber şanı da yürür
İlmin afakını duman mı bürür
Asıl aşk ebedi, hay Çıtak Ahmet
(...)

7 Elbistan Postası gazetesinde 30.09.1957 tarihinde yayımlanmıștır 
Kale muhtarina kizmak istemem

Methiye, hicviye yazmak istemem

"Malamatlı arktır, yüzmek istemem

Deryaya gidiyor çay Çıtak Ahmet

(...)

Yastığl çok serttir, yată̆l dere

Söyle ismi nedir, mekânı nere

Dal ey yaşll şair çok derinlere

Sen de içer misin mey Çıtak Ahmet

Vasfi"den sizlere selam geliyor

Murat almak için dua diliyor

Her zaman her yerde herkes biliyor

Efendi, ăga ve bey Çitak Ahmet"

Ahmet Çıtak'ın yedi dörtlükten oluşan şiirine karşılık olarak on sekiz dörtlük ile cevap veren Hayati Vasfi, rakibinden yetmiş dörtlük uzunluğunda yazılmış olan bir şiiri cevap olarak almıştır. Bu vesile ile Ahmet Çıtak, muhatabına söyleyecek söz bırakmamış dedirtecek uzunlukta, nitelikte ve etkide bir şiir yazmıştır. Havza'nın o dönemde yaşayan en kuvvetli halk şairi kabul edilen Çıtak, sanki gecesini gündüzüne katarak böyle uzun soluklu bir şiir metni kaleme almıştır. Hayati Vasfi'nin kendisine gazetede çalım sattığını ilk dörtlükte dile getirerek başlamıştır. Aslında ilk dörtlükteki “çalım satmak” deyimi muhataba çok ağır saldırıların olacağını haber vermektedir. "Korkarım ki geri kalın Hayati /Ne tükenmez kıyl u kâlin Hayati; Meşhur kelam; âmâ olan bir göze /Ne faydası olur milin Hayati " diyerek bu ve diğer dizelerde de rakibini ağır bir şekilde eleştirmiştir. Söz konusu “atışma”dan alınan dörtlükler şöyledir: 


\section{Hayatî ${ }^{8}$}

Bir boş sevda, dimağın derildi

Korkarım ki geri kalın Hayati

Gazetede çalımınız görüldü

Ne tükenmez klyl u kâlin Hayati

Niçin bilmem meydan okudun bize

Başa çıkar isen aferin size

Meşhur kelam; âmâ olan bir göze

Ne faydasi olur milin Hayati

Köye semt oluyor birisi deha

(Te) ile (mim) (sin)de beş yüzü aha

Ol altı (vav) yede baksene (vav)a

Yiğirmi de (kaf)tan çalan Hayati

(...)

Ahmet Çıtak daim şair arlyom

Her zaman karşında hazır duruyom

Üç yüz altmış beş gün mühlet veriyom

Sualimi aran bulun Hayati"

Bunun üzerine; Elbistan Havzası'nın “Aksakallı Dede Korkut” $u$ kabul edilen Bahaettin Karakoç'un Ahmet Çıtak’ a yönelik “Azarlı Mektup” ${ }^{9}$ adlı eleştirel yazısı aynı gazetede yayımlanmıştır. Mektup her ne kadar Ahmet Çıtak'a hitaben yazılmış bir mektup olsa da aslında gazetede şiirleri yayımlanan bütün kalem şairlerine yönelik bir edebi eleştiri niteliğindedir. Karakoç’un söz konusu mektup türündeki yazısı aşağıda verilmiştir:

8 Ahmet Çıtak, kendisinin yedi dörtlükten oluşan atışmasına Hayati Vasfi Taşyürek’in on sekiz dörtlükle cevap vermesini adeta gurur meselesi yapan Ahmet Çıtak, yetmiş dörtlükten oluşan bir karşı cevap hazırlar. Cevap niteliğindeki karşılaşma olduğunu düşündüğümüz bu şiir, 04.111957, 06.11.1957 ve 09.11.1957 tarihli Elbistan Postası gazetesinde yayımlanır. 9 Bahaettin Karakoç, Ahmet Çıtak’ın Hayati Vasfi Taşyürek’e cevap niteliğinde yazdığı yetmiş dörtlükten oluşan bu şiirini hem uzunluğu, hem de içerik ve şiir tekniği bakımından eleștirmiş ve bu eleştiri yazısı Elbistan Postası gazetesinin 18.11.1957 tarihli 44. Sayısında yayımlamıştır. 
“Sayın Çıtak,

Öteden beri Halk Şiiri ile ŭgraştı̆̆ınızı zaman zaman bu ürünlerinizi yerel gazetelerde neşrettiğinizi biliyor ve kovuşturuyorum. Bu sanat işinize kendinizi verdiğiniz için de bizim kuşaktan çok ileride olduğunuz için de sayarım sizi. Gel gör ki bir kimseyi saymak, onun hakkında doğru konuşmamıza dizgin vuramıyor. Vallahi sabrımızı taşırdınız artık.

“Elbistan Postası”"nda genç ve genç olduğu kadar da sanat cephesi çok kuvvetli bir şairimiz Hayati Vasfi Taşyürek”e meydan okuyan 70 kıtalık gereksiz bir şiirinizi okudum.

Efendim, gerçek şiir kafiye demek, moloz yı̆̆ınları gibi dörtlükleri sıralamak demek ve nihayet sizin anladı̆̆ınız gibi muamma demek değildir. İlhamlarınızı ve çabanızı böyle çiğ konulara harcamaya gönlüm razı olmuyor doğrusu. Şair misiniz, meddah misinız belli olmuyor.

Örneğin halk edebiyatımıza ölümsüz imzalar basan ozanlara çevirelim gözümüzü. Hangisi sizin seviyenize düşmüştür hiç. Karacaoğlan”da, Emrah"ta, Köroğlu”nda, Dadaloğlu”da, Zihni”de, Derdiçok”ta, Aşsık Veysel”de hiç böyle çirkin motişere neden rastlanmaz bilir misiniz? Sanatı çok ciddiye aldıklarından, samimi olduklarından ve nihayet yaşadıklart toplumun psikolojisini verdikleri için sivrilmişlerdir, bunlar. Çağlarında fazla bir şey yaptıklarını hiç iddia etmemişlerdir.

\section{(...)}

Ĕ̆er sanata hizmet etmek istiyorsanız, söyleyişlerinize bir yenilik katın, az fakat özlü eserler tertip edip verin bize. Renkli ve ruhlu olsun eserleriniz. Yoksa terk edin bu şiirle uğraşma dalgasını azizim, terk ediniz. Gayemin yıkmak ve köreltmek olmadığııı da bilmenizi dilerim. Hoşça kalınız."

Bu metinlerden başka Elbistan Havzası'nda halk şiirinin üç seçkin ismi; Ahmet Çıtak, Kamil Bozkurt ve Abdurrahim Karakoç arasında 1957 yılında gazetede yayımlanmış olan atışma örnekleri mevcuttur. Dönemin tanınmış şairlerinden Ahmet Çıtak, Elbistanlıların kış mevsiminde çektikleri güçlükleri bir şiirle dile getirir. Bir müddet sonra, son dönemin önemli bir halk şairi olan Abdurrahim Karakoç, Çıtak'ın kıştan şikâyetine cevap niteliğinde karşılık vermiştir. “uçan 
kuştan yardım ummak, sözün saçma sapan söylenmesi, içinizde gevrer iman, hakikatin aksi şiir yazmak" gibi ifadeler rakiplerin birbirlerini iğnelemeleri ve gülünç duruma düşürmek istemeleri amacını taşıdığından bu şiir atışma olarak adlandırılmıştır. Söz konusu “atışma” şöyledir:

\section{Çıtak:}

“Gazab-ı ilahi tükenmez klşın

Söylesem derdini roman Elbistan

Odun yok, sahip yok, belalı başın

Uçan kuştan yardım uman Elbistan

\section{Karakoç:}

Tanrı'nın kışına gazaptır dersin

Sözün saçma-sapan bil Ahmet Çıtak

Muhit başkalaşır değişir mevsim

Yağar yağmur, akar sel Ahmet Çıtak

\section{Çıtak:}

Esnaflar açamaz çarşı pazarı

Buz tutar kaş, kibrik, bıyık üzeri

Don olur deşilmez ölü mezarl

Içinizde gevrer iman Elbistan

\section{Karakoç:}

Hangi kışın kaldık çarşı pazarsız?

Hakikatın aksi şiir yazarsız

Söyle kaç ölümüz kaldı mezarsız?

Lutfeyle cevabın sal Ahmet Çıtak” (Özalp 2017: 39-40)

(...)

Abdurrahim Karakoç'un Çıtak'a cevap vermesi Elbistanlı bir başka halk şairi, Kâmil Bozkurt'u harekete geçirmiştir. Bozkurt, Karakoç'a ölçülü olmasını tavsiye niteliğinde bir şiir yazmıştır. Karakoç, bu tavsiye niteliğindeki şiire daha üst perdeden bir karşılık vermiştir. Karakoç, önemli bir taşlama şairi olduğunu 
göstermiş, ilk kez bu şiirleri ile bu yönünü ortaya koymuştur. Okuyucuyu tebessüm ettiren "kara genç, bir kılı seksene yarmak, karın kaymakamı karga, ambar gibi mide, alışkın gaga, yutar gördüğ̈̈nü çiğ hatır zade" gibi mizahi ifadeler ile oluşan Bozkurt ile Karakoç'un “atışma” "sı şu şekildedir:

\section{Bozkurt:}

“Kara Genç Çıtak'a şiir yazmışsın

Kll çok ince, kırka yaraman kuzum

Ölmeden elinle kabrin kazmışsin

Birakmam yakanı giremen kuzum

\section{Karakoç:}

Bırak bunu, senin söze gelelim

Ama kizma, biraz makul olalım

Ben bir kll tam seksene yararım

Inanmazsan gel de say hatır zade

\section{Bozkurt:}

Kar'ın kaymakamı karga olmaz mı?

Insan olan bu maksadı bilmez mi?

Üç-beş kişi her yıl kıştan ölmez mi?

Ormana uçup da varaman kuzum

\section{Karakoç:}

Kar'in kaymakamı olsaydı karga

Sen vali olurdun şimdi mutlaka

Ambar gibi mide, alışkın gaga

Yutar gördüğ̈̈n̈̈ çiğ hatır zade”(Özalp 2017: 40-41)

(...)

Daha sonra Kâmil Bozkurt, kendi ustalığını gösterir nitelikte "Ebced-i Kebirden Bir Sual” adlı bir muamma yazmış ve Karakoç'un bunu çözmesini istemiştir. Gazetede yayımlanan söz konusu “muamma” şöyledir: 
“Bir muamma neşr olundu, her gerekli bundadır

Evvelinde kaf yazılı, son hitamı nundadır

Bin dört yüz altmış yedidir âdeti ebced hesap

Harfi dokuz koy da ara, yedi nokta andadır

Yazda enbât-l turabi, kışta gelir bazara

Bir kısmeti can doğurur, bir yanı da sendedir

Yemek içmek asla bilmez, bir ziyansız nesnedir

Görmek istersen görürsün, deme ki bu kandadır?

Dört gerek ile bir olur, her bir insan yapamaz

Birisi çinden polattır, gerisi hep yandadır

Adı iki dadı yoktur, yemek için yaramaz

Bunu bilmeyen bir insan, gözleri kör mandadır

Bu muamma sahibinden hazzeder Kâmil Bozkurt

Bazı kerre cıblak olur, bazı kerre kındadır" (Özalp 2017: 41)

Bozkurt, yukarıdaki muammadan sonra Karakoç'un cevap vermesine zaman tanımadan ona hitaben "bahr-i Atlas derin, yüzemen, gölde ördek ol, kuzum ve ruhun hasta" ifadelerini kullanarak onu gülünç duruma düşürmek maksadiyla atışma niteliğinde bir şiir daha yazıp gazeteye göndermiştir. Gazetede yayımlanan şiirin bir bölümü aşağıya alınmıştır:

Bahr-i Atlas derin, yüzemen gözüm

Hele gölde ördek ol da görelim

Boş petekten gıda alınmaz kuzum

Arı ol balınan dol da görelim

Hicviye günahtır, o bizde yoktur

Yüz adet ă̆zın var, o sizde çoktur

Ruhun hasta, çare bulamaz doktur

Derdine bir derman bul da görelim

(...) 
Kâmil Bozkurt der ki, ulaşmaz elim

Şairine göre söz söyler dilim

Ebced-i kebirden konuş ki bil'im

Bütün inceliğin telde görelim” (Özalp 2017: 42)

Ancak Abdurrahim Karakoç, Bozkurt'un yaşına ve tecrübesine saygı duyduğundan bu aşamadan sonra kırıcı olmamak için bir cevap vermemiş ve söz konusu atışma, bu haliyle sona ermiştir. Albayrak'1n (2004:41) ifade ettiği gibi atışmalarda bir âşı̆̆ın diğerini yenmesi, yani sözün bitmesi diye bir şey söz konusu değildir. Bu atışmanın da bir mağlubu yoktur.

Gazetede icra edilen bir diğer örnek ise Afşinli Osman Konak ile Cuma Şahin' in yaptığ 1 deyişmedir. 10 Kasım 1975 tarihli Elbistan Postası gazetesinde yayımlanmıştır. Yazılı kültür ortamında 8'li hece ölçüsüyle yazılmış, ortak ayaklı bu metinler, "sohbet" esasına dayandığından deyişme tarzına örnek niteliktedir. Söz konusu “deyişme"nin bir bölümü şöyledir:

\section{"Şahin:}

Fakirin yanarsa özü

Çıkar dumanı dumanı

Görmezse zenginin gözü

Var mı imkânı imkânı

\section{Konak:}

Yoksul düşse pençesine

Bilmez âmânı âmânı

Hemen takar kancasina

Gaddar zamanı zamanı

\section{Şahin:}

Yoksulluk düşürür çaptan

Gemiye almiyor kaptan

Fayda olmayan tabipten

Kestik gümanı gümanı 


\section{Konak:}

Ne sevinç var ne de neşe

Dertlerimiz köşe köşe

Bak didemden akan yaşa

Islar çimeni çimeni

(...)"

Yukarıda belirtildiği gibi muhtelif tarihlerde “Elbistan Postası" gazetesinde yayımlanan "karşılaşma-atışma-deyişmeler”den sonra yıllar içinde yerel gazetelerde bu tarz şiirler yayımlanmış fakat metinler ilk örnekler kadar ilgi uyandırmamıştır.

2006 yılından itibaren "gazete” halk şairleri tarafından daha etkin kullanılmaya başlanmıştır. Yazılı kültür ortamında icra edilen karşılaşma, atışma ve deyişme geleneği yeniden canlı bir şekilde varlığını göstermiştir.

Mehmet Gözükara, Hacı Hasan Uğur, Ahmet Bulut, Ali Başpınar, Arif Taşkale, Can Uğur, Erol Boyunduruk (Giryani), Eyüp Şahan, Fatma Kalkan, Haşim Kalender, İsmail Kutlu Özalp, M. Ali Kepez, Mahir Başpınar, Mesut Türkkahraman, Osman Konak, Ramazan Pamuk, Saliha Değirmenci gibi şairler tarafindan karşılaşma, atışma ve deyişme tarzında şiirler yazılmaya ve yerel gazetelerde yayımlanmaya başlamıştır. Bu gelenek, uzun y1llar sonra ilk olarak 2006 yılında Hacı Hasan Uğur ile Mehmet Gözükara'nın Haber Elbistan gazetesinde yayımlanan ve ses getiren şiirleriyle yeniden kendini hissettirmiştir.

\section{Gazetelerde Yayımlanmış Karşılaşma-Atışma-Deyişme Ör- neklerini İçeren Kitaplar}

“Boyun Büktüm Güle Doğru, Namluya Şiir Sürdüler-Atışma, Şiir Döşsedik Yollarına Elbistan' ın Afşsin 'in ve Söz Kuşand Şairler Kılıçtan Keskin-Atışmalar" adlı karşılaşma, atışma ve deyişme muhtevalı bu dört eser, ilk önce Elbistan Havzası'ndaki yerel gazetelerde yayımlanmış ve daha sonra kitaplaştırılmıştır.

Bu geleneğin yaşamasına ve 2006' dan itibaren gazetelerde yer alan 'karş1laşma, atışma ve deyişme" örneklerinin kitaplaştırılmasına katkı sağlayan kişiler Mehmet Gözükara ve Arif Bilgin'dir. Gözükara ve Bilgin Elbistan Havzası'nda yayımlanan yerel gazetelerde yazan eli kalem tutan köşe yazarlarıdır. Aynı za- 
manda her ikisi de halk şiiri tarzında eser veren kalem şairleridir. Bunlar, Elbistan Havzası'ndaki halk şairlerinin şiirlerini gazete ortamında kendi köşelerinde yayımlayarak halk şairlerinin şiirlerini okuyucuyla buluşturmuşlardır. Bu şahıslar, yöredeki halk şairlerini gazete ortamında karşılaşma, atışma ve deyişme yapmaları için yüreklendirmiş ve bu geleneğin devam etmesine yazılarıyla destek olmuşlardır. Bu kişiler, aynı zamanda gazetede gerçekleşen karşılaşma, atışma ve deyişme etkinliklerini organize eden şahsiyetlerdir. Hem Gözükara hem de Bilgin, gazete köşelerindeki ve kitaplardaki metinleri atı̧̧ma olarak adlandırmışlardır. Ancak bu metinlerin tamamı atışma özelliği taşımamaktadır. Yukarıdaki gazetede yayımlanan örneklerin isimlendirilmelerinden de anlaşılacağı gibi metinlerin bazılarının atışma (mizahi bir dille eleştirme, alay etme, güldürme) ve bazılarının da deyişme (sohbet etme) olduğu tespit edilmiştir.

Boyun Büktüm Güle Doğru (Gözükara 2007) adlı eser Mehmet Gözükara tarafından yayına hazırlanmıştır. Namluya Şiir Sürdüler-Atışma (Bilgin 2008) ve Şiir Döşedik Yollarına Elbistan'ın Afşin'in (Bilgin 2010) adlı eserler de Arif Bilgin'in gazete köşesinde yayımladığı farklı halk şairlerine ait atışmaların kendisi tarafindan bir araya getirmesiyle oluşmuştur. Söz Kuşandı Şairler Kllıçtan Keskin-Atışmalar (Gözükara 2012) adlı eser ise Mehmet Gözükara'nın halk şairlerine ait şiirleri konu edinerek oluşturduğu gazete köşesindeki yazılarının derlemesiyle meydana gelmiştir.

1-Boyun Büktüm Güle Doğru (Gözükara 2007): Bilgin, Haber Elbistan gazetesindeki "Gönlümce" adlı köşesinde 28 Şubat 2006 tarihinde Hacı Hasan Uğur ile Mehmet Gözükara'nın atışmasının başlayacağını "Gözükara-Uğur Atışması"10 adlı yazısıyla duyurmuştur. Ayrıca o, bu yazısında halk şiirindeki atışma geleneği hakkında bilgilere de yer vermiştir. Onun yazısının son kısmında ise gazetede yayımlanacak olan Gözükara-Uğur Atışması'nın haftaya başlayacağ haberi yer almıştır. Bu karşılaşma, atı̧̧ma ve deyişmelerin tamamı 10 Mart 200615 Nisan 2006 tarihlerinde Haber Elbistan gazetesinde Bilgin'in gazetedeki köşesinde yayımlanmıştır (Gözükara 2007: 147-176). "Boyun Büktüm Güle Doğru” eserinin malzemelerini oluşturan süreç bu şekilde başlamıştır. 
Boyun Büktüm Güle Doğru adlı eser, Elbistan Havzası'nda yerel gazetede yayımlanan karşılaşma, atışma ve deyişme olarak söylenen şiirlerin bir araya getirilmesi ile oluşan ilk kitaptır bölümüdür. Eser, iki bölümden oluşmaktadır. Birinci bölüm, Gözükara'nın değişik şekil ve türdeki halk şiirlerinden meydana gelmiştir. İkinci bölüm ise Arif Bilgin'in Haber Elbistan gazetesindeki köşesinde yazı dizisi şeklinde yayımlamış olduğu "Uğur-Gözükara Atışması"nı içermektedir.

"Boyun Büktüm Güle Doğru” adlı eserin ikinci bölümünde Mehmet Gözükara'ya ait 7 şiir yer alırken karşılaşma yaptığı rakibi Hacı Hasan Uğur'un 5 şiir bulunmaktadır. Bu iki şair arasındaki çekişmenin büyümemesi için araya onları barışa davet eden şairlerin şiirleri girmiştir. Bu şairlerin ve şiirlerinin isimleri katılım sırası şöyledir: "Âşık Süleyman Kara, Barış Çağrısı-Can Ŭ̆ur, Şairlere Sesleniş-Âşık Mahrumi, Bu Ne Savaş1-Ahmet Bulut, Yarışan Şairler-Serhat Özdemir, Barış Çağrısı-Haşim Kalender, Devamından Yanayım-Nevzat Bayrı, Uğur Amca İle Gözükara Dayıma Saygılarımla-Bünyamin Doğan, Biri Bitter Biri Şeker-Bekir Yalçın, Barışa Çağrı-Âşık Mahrumi, Barıştırın Bunları.”

Bilgin'e göre Mehmet Gözükara'nın usta bir şair olan Hacı Hasan Uğur ile karşılaşma-atışma-deyişme yaparak adını duyurmak istemesi böyle çalışmanın oluşmasında etkili olmuştur. Ortaya konulan metinler rakibi mat etmeyi ve kendini üstün görmeyi konu edindiği için “karşılaşma” türündedir.

Söz konusu kitabın ikinci bölümünde yer alan karşılaşmanın taraflarından biri olan Hacı Hasan Uğur, Havza'da saygı duyulan bir şahsiyettir. Bir kalem şairi olan Uğur'un şiirleri yöre halkı tarafından beğeniyle okunmaktadır.

Rakibi ise Mehmet Gözükara'dır. Onun yetişmesinde özellikle annesi Güllü Gözükara'nın büyük etkisi vardır. Güllü Hanım, Havza'nın yetiştirdiği önemli halk şairlerinden biridir. Aynı zamanda yörenin gelenek ve göreneklerini benimseyen bir Anadolu kadınıdır. Bu sebeple Mehmet Gözükara'nın şiirlerinde halk irfanının derin izlerini bulmak mümkündür. Gözükara'nın sanatçı kimliğinin oluşmasında gelenekten yola çıkarak onu yeniden yorumlayan ve belli bir estetik anlayışla günümüze ulaştıran XX. yüzyılın önemli söz ustalarından olan Abdurrahim Karakoç'un etkisi de görülmektedir. Etkili bir söyleyiş tarzına sahip olan Gözükara'nın beğenilen bir kalem şairi olarak kabul edilmesini aynı çağda ve aynı kültür coğrafyasında yaşayan Karakoç’tan etkilenmesine bağlamak mümkündür. 
“Boyun Büktüm Güle Doğru” adlı eser, gazetede yayımlanan karşılaşmaların ilk defa bir kitapta yer alması bakımından önemlidir.

2-Namluya Şiir Sürdüler - Atışma (Bilgin 2008): Arif Bilgin’in 2006 y1lında "Haber Elbistan" gazetesindeki "Gönlümce” köşesinde yayımlanan karşılaşma, atışma ve deyişmelerden oluşan yazı dizisinden sonra hem Elbistan Havzası halk şairleri hem de bu köşeyi takip eden okurlar yeniden buna benzer bir çalışmanın gerçekleşmesi için gazeteden talepte bulunmuştur.

Bunun üzerine bir önceki çalışmada olduğu gibi yine Arif Bilgin'in gazete köşesindeki yazı dizisinde karşılaşma, atışma ve deyişmeleri aktaracağı gazete haberiyle duyurulmuştur. Bu söyleşmenin iki halk şairiyle sınırlı olmayacağı ve Elbistan Havzası'nın tüm şairlerinin hatta komşu il ve ilçelerdeki halk şairlerinin de katılabileceği de haberde yer almıştır. Söz konusu habere göre hangi şairin haftanın hangi günlerinde şiir göndereceği de belirtilmiş ve ilk eserin 29 Ekim 2007 Pazartesi günü yayımlanacağı bilgisine yer verilmiştir (Bilgin 2008: 7-10). Bu yazı dizisi gazetede iki ay devam etmiş ve 31.12.2007 tarihinde tamamlanmıştır.

Eserde şiirleri olan şairler şunlardır: Ahmet Bulut-Mehmet Gözükara Atışması (Bilgin 2008:11-48), Mehmet Gözükara-Salih Ballı Atışması (Bilgin 2008: 57-68), Ahmet Bulut-Salih Ballı Atışması (Bilgin 2008: 69-78), Mehmet Gözükara-Hacı Hasan Uğur Atışması (Bilgin 2008: 79-96), Afşinli Giryanî'nin Elbistanlı Şairlere (Gözükara, Bulut, Ballı, Pamuk ve Kepez) Meydan Okuması (Bilgin

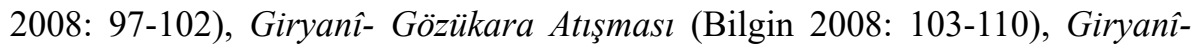
Ahmet Bulut Atışması (Bilgin 2008: 111-126), Giryanî-Salih Ballı Atışması (Bilgin 2008: 127-138), Giryanî-Ramazan Pamuk Atışması (Bilgin 2008: 139-150),

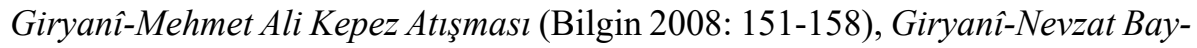
rı Atışması (Bilgin 2008: 159-164).

Daha sonra Haber Elbistan gazetesinde yayımlanan yazılar ve şiir metinleri Arif Bilgin tarafından bir araya getirilip düzenlenmiş ve "Namluya Şiir Sürdüler-Atışma” adıyla kitap olarak bastırılmıştır. Bu eser, Elbistan Havzası'nda çıkan ilk müstakil yazılı kültür ortamı karşılaşma, atışma ve deyişme kitabı olması bakımından kayda değer bir çalışma olarak kabul edilmiştir. 
3-Şiir Döşedik Yollarına Elbistan'ın Afşin'in (Bilgin 2010): Bu çalışma, Havza'nın usta halk şairlerinin katılımıyla Haber Elbistan, Yeşil Afşsin gazetelerince düzenlenen karşılaşma, atışma ve deyişme tarzında şiirlerin yayımlanmasıyla ortaya çıkmıştır. Afşin'den Erol Boyunduruk, Arif Taşkale ve Mesut Türkkahraman; Elbistan'dan Ramazan Pamuk ile Ahmet Bulut gibi usta şairler katılmıştır. Gazetede yayımlanacak olan bu karşılaşma, atışma ve deyişme faaliyetinin sağlıklı bir şekilde gerçekleşmesi için Afşin'den Osman Konak ile Ali Başpınar, Elbistan'dan Hacı Hasan Uğur ortamı yumuşatıcı şiirleriyle katkıda bulunmuşlardır. Arif Bilgin tarafından düzenlenen ve yazı dizisi şeklinde tefrika edilen bu metinler eş zamanlı olarak 26 Kasım 2008-10 Şubat 2009 arasında Haber Elbistan ve Yeşil Afşsin gazetelerinde yayımlanmıştır.

Eserde aşağıdaki şairlerin şiirlerine yer verilmiştir: Arif Taşkale-Ahmet Bulut Atışması (Bilgin 2010: 53-84), Ahmet Bulut-Erol Boyunduruk Atışması (Bilgin 2010: 85-104), Ahmet Bulut ve Mesut Türkkahraman Atışması (Bilgin 2010: 105-132), Ramazan Pamuk (Hilkati) Erol Boyunduruk (Giryani) Atışması (Bilgin 2010: 133-160), Ramazan Pamuk (Hilkati) İe Mesut Türkkahraman Atışması (Bilgin 2010: 161-194), Ramazan Pamuk (Hilkati) ile Osman Konak Sinaması (Bilgin 2010: 199-202), Ramazan Pamuk ile Arif Taşkale Sinaması (Bilgin 2010: 203-206), Hilkati ile Ali Başpınar (Çöteli) Sınaması (Bilgin 2010: 207-210).

Gazetelerde yayımlanan değerlendirme yazıları ve şairlerden gelen şiir metinleri daha sonra Bilgin tarafından bir araya getirilmiş ve 2010 yılında "Şiir Döşedik Yollarına Elbistan 'ın Afşin 'in ” adıyla kitap olarak bastırılmıştır. Bu eser, sadece Elbistan şairlerin şiirlerini değil aynı zamanda Elbistan Havzası'nın diğer ilçelerindeki şairlerin şiirlerini de içermesi bakımından önceki iki eserden ayrılmaktadır. Aynı zamanda birden fazla yerel gazetede yayımlanmış olması da yazılı ortamdaki karşılaşma, atışma ve deyişme geleneğine yöre halkının ilgisini göstermesi bakımından önemlidir.

4-Söz Kuşandı Şairler Kılıçtan Keskin -Atışmalar (Gözükara, 2012): Mehmet Gözükara, gazete ortamında karşılaşma, atışma ve deyişme geleneğine katkı sağlamak için Havza'nın önemli şairleri olarak gördüğü sanatçılarla ve Haber Elbistan gazetesinin sahibi Ahmet Göçer ile istişare etmiş, onların olumlu görüşleri üzerine böyle bir çalışma yapmaya karar vermiştir. 
Gözükara, şairleri “Atışmamıza, Türkiye’nin hatta dünyanın neresinden olursa olsun, her şair katılabilir. Buyursunlar gelsinler. Kim kimle atışmayı diliyorsa onunla atışsın. Gönlümüz ve atışmamız herkese açıktır.” (2012: 13) diyerek davet etmiştir

Bunun üzerine Mehmet Ali Kepez Fransa'dan, Saliha Değirmenci Yavaş Konya'dan, Fatma Kalkan Artvin'den, Mahir Başpınar Göksun'dan, Eyüp Şahan Ankara'dan, Hacı Hasan Uğur Elbistan'dan, Ahmet Bulut Elbistan'dan, Haşim Kalender Afşin'den, İsmail Kutlu Özalp İstanbul'dan, Erol Boyunduruk Afşin'den, Osman Konak Afşin'den ve Can Uğur Elbistan'dan Haber Elbistan gazetesine şiirler göndererek yazılı kültür ortamında gelenekselleşen karşılaşma, atışma ve deyişmeye katılmışlardır (Gözükara 2012: 13-14).

Yapılan programa göre; pazartesi-Mehmet Gözükara, sall-Ahmet Bulut, çarşamba-Haşim Kalender, İsmail Kutlu Özalp, M. Ali Kepez, perşembe-Erol Boyunduruk, Eyüp Şahan, Hacı Hasan Uğur, cuma-Fatma Kalkan, İsmail Kutlu Özalp, Mehmet Gözükara, cumartesi-Saliha Değirmenci Yavaş, İsmail Kutlu Özalp ve Mehmet Gözükara'nın şiirleri yayımlanmıştır. İcra, haftada altı gün olmak üzere üç ay boyunca belirtilen programa göre devam etmiştir. ${ }^{11}$

Eserde yer alan şiirler şu şairlere aittir: Mehmet Gözükara ve Ahmet Bulut Atışması (Gözükara 2012: 19-58), Mehmet Gözükara ve İsmail Kutlu Özalp Atışması (Gözükara 2012: 59-116), Mehmet Gözükara ve Haşim Kalender Atışması (Gözükara 2012: 117-149), Ahmet Bulut Ille Erol Boyunduruk (Giryani) Atışması (Gözükara 2012: 151-166), Mehmet Gözükara İle Erol Boyunduruk (Giryani) Atışması (Gözükara 2012: 167-189), Ahmet Bulut Ile Eyüp Şahan Atışması (Gözükara 2012: 190-210), Mehmet Ali Kepez Ile Erol Giryani'nin Atışması (Gözükara 2012: 211-236), Ahmet Bulut Ile Mehmet Ali Kepez Atışması (Gözükara 2012: 237-252) Mahir Başpınar İle Mehmet Gözükara Atışması (Gözükara 2012: 253-278), Mahir Başpınar İle Erol Giryani Atışması (Gözükara 2012: 279-308), Mehmet Gözükara Ile Hacı Hasan Ŭ̆ur Atışması (Gözükara 2012: 309-318), Mehmet Gözükara İle Fatma Kalkan Atışması (Gözükara 2012: 325-344), İsmail

$11 \mathrm{Bu}$ eseri oluşturan şiirler 20 Ekim 2011 -20 Ocak 2012 tarihleri arasında Haber Elbistan gazetesinde Mehmet Gözükara'nın köşesinde yayımlanmıştır. Daha sonra bu yazı dizisinin tamamını elektronik ortamda http://www.elbistaninsesi.com/elbistanin-hikyesi-yeniden-yaziliyor-makale,5460.html adresinde 01.01.2012 tarihinde yayımlamıştır. Yazı dizisine bu adresten “Mehmet Gözükara’nın Önceki Yazıları” bölümünden ulaşabilirsiniz. 
Kutlu Özalp İle Erol Giryani Atışması (Gözükara 2012: 345-368), Saliha Değirmenci Yavaş (Zühre) Ile İsmail Kutlu Özalp (Kutlu) Atışması (Gözükara 2012: 369-382), Saliha Değirmenci Yavaş (Zühre) İle Fatma Kalkan (Çoruh'un Klzı) (Gözükara 2012: 38,-390), Erol Giryani İle Fatma Kalkan Atışması (Gözükara 2012: 391-403).

Söz konusu eser, "Haber Elbistan" gazetesinde 20 Ekim 2011-20 Ocak 2012 tarihleri arasında Mehmet Gözükara'nın yukarıda adları zikredilen halk şairlerinden gelen karşılaşma, atışma ve deyişmeleri ihtiva eden şiirleri gazetedeki köşesinde yazı dizisi halinde yayımlaması ve daha sonra bu metinlerin düzenlenip bir araya getirmesiyle oluşmuştur. Bu metinlerin arasında Gözükara'nın şiirleri de yer almıştır. Eser, "Söz Kuşandı Şairler Kıllıçtan Keskin -Atışmalar" adıyla yayınlanmıştır. Bu eser, Elbistan Havzası dışından katılan halk şairlerinin şiirlerini de ihtiva etmesi bakımından diğer eserlerden farklılık göstermektedir.

\section{Sonuç}

Elbistan Havzası, kültür ve medeniyet yönünden gelişmiş bir coğrafyadır. Söz konusu gelişmişlik, Türk halk şiiri geleneğinin de bu yörede canlı bir şekilde varlığını sürdürmesine katkı sağlamıştır. Halk şiir geleneği bazı dönemlerde çeşitli tercihler sebebiyle beklenen ilgiyi görmemiş olsa da her zaman varlı̆̆ını sürdürmüştür.

Toplum hayatındaki değişim ve dönüşüm, halk şiirinin sadece sözlü ortamda değil aynı zamanda yazılı ve elektronik ortamlarda da kendini göstermesine vesile olmuştur. Buradan hareketle çalışmada, halk şairlerinin şiirlerini icra ettikleri yazılı kültür ortamı üzerinde durulmuş ve kültür ortamlarının geçişlerindeki “art zamanlılık-eş zamanlılık ilişkisi” konusuna değinilmiştir

Yörede yetişmiş olan halk şairlerinin bu yüzyılın ikinci yarısından sonra halk şiirinde önemli kabul edilen "karşılaşma, atışma ve deyişme" tarzındaki şiirleri yazarak yerel ve ulusal gazetelerde yayımlamışlardır. Yazılı kültür ortamında oluşan bu eserlerde ele alınan konular "sözlü gelenekle” benzerlik göstermektedir. Şiirlerini yazılı kültür ortamında icra eden şairler; mizah, hiciv ve yergi gibi türlerde üstünlüklerini gösterme gayretine girmişler ve dikkate değer karşılaşmalar, atışmalar ve deyişmeler ortaya koydukları görülmüştür. Bu alanda yapılan ça- 
lışmalardan da faydalanılarak Elbistan Havzası'ndaki yazılı ortamdan elde edilen karşılaşma, atışma ve deyişme örnekleri tasnif edilmiştir.

Elbistan Havzası'ndaki yerel gazetelerde yayımlanan karşılaşma, atışma ve deyişme örnekleri kitaplaştırılmış ve bu sayede gazete köşelerinde dağınık olarak yer alan metinler belli bir tertip içinde düzenlemiştir. Hem sistematik olması hem de söz konusu geleneğin gelecek nesillere sağlıklı bir şekilde ulaşma imkânı sunması bakımından bu eserler önem arz etmektedir.

Halk şiiri sahasında terminoloji bakımından tartışmalı konulardan biri olan karşılaşma, atışma ve deyişme gibi türler hakkında bilim insanlarının görüşlerine yer verilmiş, bu görüşlerdeki farklılık arz eden hususlara dikkat çekilmiş ve makalede terminolojideki problem daha belirgin şekilde ortaya konulmuştur. Çalışmada ele alınan gazetelerde ve kitaplarda yayımlanmış şiirlerin tamamının "atışma" olarak adlandırıldığ 1 tespit edilmiştir. Yapılan tetkikler sonucunda yayımlanan bu örneklerin bazılarının "karşıllaşma", bazılarının "atışma", bazılarının da "deyişme" olduğu sonucuna varılmıştır. Bu hususta günümüze kadar yapılan çalışmalar, karşılaşma, atışma, deyişme arasındaki farkları kesin bir şekilde ortaya koymuştur. Ancak söz konusu problemi çözmek için sahadan tespit edilecek çok sayıda örnekle bu türlerin tanımları daha da somutlaştırılmalıdır. 


\section{Kaynakça}

Akyıldız, A. (2018). Engizek Yerel Gazete. (ed.) İ. Solak, Kaharamanmaraş Ansiklopedisi (Cilt III, s. 324-329). Kahramanmaraş: Kahramanmaraş Sütçü İmam Üniversitesi.

Albayrak, N. (2004). Halk Edebiyatı Terimleri Sözlüğü, İstanbul: Leyla İle Mecnun Yayınları.

Atmaca, S. (2018). Kahramanmaraşlı Kalem Şairlerin Atışma Örnekleri, Sosyal Bilimler Dergisi / The Journal Of Social Science Y11: 5, Say1: 19, Ocak 2018, S. 178-203.

Artun, E. (2011). Aşılklı Geleneği ve Aşık Edebiyatı Edebiyat Tarihi/Metinler. Adana: Karahan Kitabevi.

Arat, R. R. (1965). Eski Türk Şiiri. Ankara: TTK Yayınları.

Avcı, R. (2014). Geleneği Yeni Şartlarda Sürdürme Çabasının Meyveleri. (hzl.) M. Gözükara, \& T. Atmaca, Söz Açarı Atışma-Şiir (s. 13-18). Ankara: Berikan Yayınevi.

Avc1, R. (2017). Şairler Eydur. (hzl.) M. Gözükara, \& İ. Özalp , İki Yürek Bir Ses Oldu Sazsız Atışma-şiir (s. 10). Ankara: SAGE Yayıncılık.

Bali, M. (1975). Aşık Karşılaşmaları,-Atışmalar. Türk Folklor Araştırmaları Dergisi, 16(316).

Başgöz, İ. (1986). Folklor Yazlları. İstanbul: Adam Yayınları.

Bilgin, A. (2008). Namluya Şiir Sürdüler-Atışma. Elbistan: Göçer Ofset.

Bilgin, A. (2010). Şiir Döşedik Yollarına Elbitan'ın Afşsin 'im. İzmir: Bassaray Matbaası.

Boratav, P. N. (1937). Folklor, Halk Edebiyatı ve Âşıłk Edebiyatı. İnsan, I(2), 137-145.

Çıkla, S. (2009). Tanzimattan Günümüze Gazete-Edebiyat İlişkisi. Türkbilig(18), 34-63.

Çobanoğlu, Ö. (2000). Aşık Tarzı Kültür Geleneği ve Destan Türü. Ankara: Akçağ Yayınları.

Duymaz, A. (2016). Sözün Yazılaşması Yazının Sözleşmesi. Milli Folklor (111), 14-27.

Eke, M. (2000). "Saz Âşıklarında Atışma (Karşılaşma, Deyişme)", , C. 6,. Folklor Edebiyat Dergisi, 6(3), 193.

Eke, M. (2010). Geçmişte Yapılan Âşık Atışmalarının Günümüzdeki Görünümü. Acta Turcica Çevrimiçi Tematik Türkoloji Dergisi, 1(II), 75-84. 08 22, 2020 tarihinde alındı

Elçin, Ş. (1992). Halk Edabiyatına Giriş. Ankara: Akçağ Yayınları.

Erşahin, İ. (2014). Takdim. (hzl.) M. Gözükara, \& T. Atmaca, Söz Açarı Atışma/Şiir (s. 9-12). Ankara: Berikan Yayınları.

Gökalp, Z. (1922). Halk Klasikleri I. Diyarbakır.

Gökalp, Z. (1981). Türkçülüğün Esasları. İstanbul: Varlık Yayınları.

Gözükara, M. (2007). Boyun Büktüm Güle Doğru. Elbistan : Bassaray Matbaası.

Gözükara, M. (2012). Söz Kuşandı Şairler Kılıçtan Keskin-Atışmalar. İstanbul: Özgü Yayınevi. 
Gözükara, M., \& Atmaca, T. (2014). Söz Açarı Atışma-Şiir. Ankara: Berikan Yayıvi.

Günay, T. (1976). Türk Şiirinde İlk Deyişme (Münazara) Örnekleri. Uluslararası Folklor ve Halk Edebiyatı Seminerleri Bildirileri. Ankara: 1976.

Günay, U. (1993). Türkiye'de Aşık Tarzı Şiir Geleneği ve Rüya Motifi. Ankara: Akçağ Yayınları.

Kafesoğlu, İ. (1988). Türk Milli Kültürü (5 b.). İstanbul: Boğaziçi Yayınları.

Kaya, D. (1999). Karşılaşma, Atışma ve Deyişme Kavramları Üzerine Düşünceler ve Feymani'den Örnekler. Folklor/Edebiyat Dergisi(20), 131-140.

Köprülü, M. F. (1915. Âşık Tarzının Menşei ve Tekâmülü. Milli Tetebbular Mecmuası, II(IV), 5-46.

Oguzbaşaran, B. (2006). Şehir ve Şiir. Somuncu Baba İlim Kültür ve Edebiyat Dergisi, 37-39.

Oğuz, M. Ö. (2006). Aşık Şiiri (XVI-XX Yüzyıl) Ozan -Baksı'dan Aşık’a Dönüşüm. (ed.) T. S. Halman, Türk Edebiyatı Tarihi (Cilt 2, s. 138-179). İstanbul: Kültür ve Turizm Bakanlığı Yayınları.

Ong, W. J. (1999). Sözlü ve Yazılı Kültür - Sözün Teknolojileşmesi.(çev.) S. P. Banon. 2. Bask1 (2 b.). (S. Postacığlu Banon, Çev.) İstanbul: Metis Yayınlaerı.

Özalp, Ö. H. (2017). İki Güzel İnsan. (hzl.) M. Gözükara, \& İ. K. Özalp, İki Yürek Bir Oldu Sazsız Atışma/Şiir (s. 38-46). Ankara: Sage Yayıncılık.

Özarslan, M. (2001). Erzurum Âşıklık Geleneği. Ankara: Akçağ Yayınları.

Özerdim, M. (1943). Çin'in Şimalinde Hanedan Kuran Türklerin Şiirleri. Dil Tarih ve Coğrafya Fakültesi Dergisi, 2(5).

Özder, M. A. (1965). Doğu İllerimizde Aşık Karşılaşmaları. Bursa.

Özgen, A. (2018). Gazete Basın Yayın Organı. (ed.) İ. Solmaz, Kahramanmaraş Ansiklopedisi (Cilt III, s. 460-465). Kahramanmaraş: Kahramanmaraş Sütçü İmam Üniversitesi Yayınları.

Özön, N. (1938). Gazeteciliğimiz ve Agâh Efendi. Kalem(1), 1-4.

Polat, C. (2009). Engizek gazetesi, 12 Nisan 1947.Engizek gazetesi, 12 Ağustos 1963. (hzl. C. Polat) Maraş Bibliyografyası (s. 190-192). Kahramanmaraş.

Şapolyo, E. B. (1971). Türk Gazetecilik Tarihi ve Her Yönüyle Basın. Ankara: Güven Matbaası.

Tanpınar, A. H. (2009). XIX. Asır Türk Edebiyatı Tarihi. İstanbul: Çağlayan Kitabevi.

Taşlıva, M. M. (2017). Âşıklık Geleneğinde Grup İcrası Group Performance in the Tradition of Minstrelsy. Milli Folklor, (113), 5-16.

Ata Yıldız, N. ve Turan, F. A. (2016). Türk Dünyası Âşık Edebiyatı. Ankara: Gazi Kitabevi.

Türkçe Sözlük. (1998). Ankara: TDK Yayınları.

Yakar, S. (2010, 12 21). marasgundem.com egitim/mahalli-gazetelerde-marasta-fikir-sanat21492h. 11 14, 2019 tarihinde marasgundem: https://www.marasgundem.com.tr/ adresinden alınd 1

Yardımcı, M. (2015). Başlangıcından Günümüze Türk Halk Şiiri. İzmir: Kanyılmaz Matbaacılık . 